\title{
DEALING WITH DENTAL IMPLANT FAILURES
}

\author{
Liran LEVIN
}

1- DMD, Department of Oral Rehabilitation, The Maurice and Gabriela Goldschleger School of Dental Medicine, Tel Aviv University, Tel Aviv, and Periodontology Unit, Department of Oral \& Dental Sciences, Rambam Medical Center, Haifa, Israel.

Corresponding address: Dr. Liran Levin - Department of Oral Rehabilitation - The Maurice and Gabriela Goldschleger School of Dental Medicine - Tel Aviv University, Tel Aviv, Israel - Fax: +972-3-6409250 - e-mail: liranl@post.tau.ac.il

Received : January 10, 2008 - Modification : February 23, 2008 - Accepted : February 26, 2008

\begin{abstract}
$A$

$\mathrm{n}$ implant-supported restoration offers a predictable treatment for tooth replacement. Reported success rates for dental implants are high. Nevertheless, failures that mandate immediate implant removal do occur. The consequences of implant removal jeopardize the clinician's efforts to accomplish satisfactory function and esthetics. For the patient, this usually involves further cost and additional procedures. The aim of this paper is to describe different methods and treatment modalities to deal with dental implant failure. The main topics for discussion include identifying the failing implant, implants replacing failed implants at the exact site, and the use of other restorative options. When an implant fails, a tailor made treatment plan should be provided to each patient according to all relevant variables. Patients should be informed regarding all possible treatment modalities following implant failure and give their consent to the most appropriate treatment option for them.
\end{abstract}

Key words: Clinical studies. Endosseous dental implants. Implant restorations. Implant survival, success. Re-implantation. Fixed denture. Removable denture.

\section{INTRODUCTION}

An implant-supported restoration offers a predictable treatment for tooth replacement ${ }^{11,23-25,29,34}$. Reported success rates for dental implants are high, however, there is still a paucity of data in the literature regarding follow-up of implants in function for at least 5 years or more ${ }^{9,20,40}$. Nevertheless, failures that mandate immediate implant removal do occur ${ }^{9,11,20,24,40}$. The consequences of implant removal jeopardize the clinician's efforts to accomplish satisfactory function and esthetics. For the patient, this usually involves further cost and additional procedures.

Reported predictors for implant success and failure are generally divided into patient-related factors (e.g., general patient health status, smoking habits, quantity and quality of bone, oral hygiene maintenance, etc), implant characteristics (e.g., dimensions, coating, loading, etc), implant location, and clinician experience ${ }^{22,33,39}$.

Cluster behavior can occur in implant failure ${ }^{19}$. The finding that implant failures are not randomly distributed in the treated populations and that implant loss clusters in specific high-risk groups and individuals was examined in a literature review ${ }^{44}$.

The aim of this paper is to describe different methods and treatment modalities to deal with dental implant failure.

\section{Identifying failing implant}

Success of dental implants is commonly defined by implant survival. Implant failure probably results from multifactorial process. There are various causes related to early (overheating, contamination and trauma during surgery, poor bone quantity and/or quality, lack of primary stability, and incorrect immediate load indication), and late (periimplantitis, occlusal trauma, and overloading) failure.

Ongoing marginal bone loss (MBL) could also put at risk implant survival in the long-term. In 1986, Albrektsson, et al. ${ }^{2}$ suggested success criteria for MBL, among other parameters. During the first year after abutment connection, $1 \mathrm{~mm}$ of MBL is allowed followed by $0.2 \mathrm{~mm}$ per year. Today, these criteria are still frequently referred to as the "gold standard" for implant success.

Recently, the abundance of data regarding MBL, and a better understanding of bone and soft tissue behavior around the implant neck and body, have shown these criteria to be inaccurate for today's wide variety of implant systems ${ }^{41}$.

An implant that causes clinical symptoms, such as continuous pain, mobility, etc, is considered faulty. However, MBL is rarely symptomatic but may endanger long-term implant survival. Although reports on the dynamics of MBL over time are incomplete, the MBL rate changes at different stages during the life of an implant. Given the accumulation of MBL data, calculations should not include a smooth polished neck portion ${ }^{41}$. Long-term prognosis of an implant cannot be established based only on first year MBL calculations. Follow-up is essential to determine and predict 
a future clinical course. Previously, we recommended that four clinically detectable MBL patterns be used for clinical follow-up and assessment ${ }^{41}$. These hypothetical patterns of implant MBL after the first year were low rate MBL over the years (Albrektsson's pattern), low rate MBL in the first few years followed by a rapid loss of bone support, high rate MBL in the first few years followed by almost no bone loss, and continuous high rate $\mathrm{MBL}$ leading to complete loss of bone support (For review see Schwartz-Arad, et al. ${ }^{41}$ ).

Criteria for implant success should serve as an aid to clinical follow-up and to help evaluate the clinical outcomes of different implant systems in research. For clinical use, MBL assessment should be easy to apply using radiographs and should allow a quick gross comparison to previous data. Together with Albrektsson's clinical parameters, it should help the clinician assess a given condition and predict its future clinical course, as well as help in decision making regarding additional tests/therapy (i.e., radiographs, occlussal analysis, prosthetic evaluation, surgical intervention, etc), frequency of follow-up, and hygiene appointments.

According to Albrektsson's clinical parameters, in a low MBL rate during the first 3 years, the MBL pattern is still undetermined in an asymptomatic implant. Frequent followup is recommended to decide whether the implant is failing. Nevertheless, long-term follow-up is suggested for all MBL patterns.

It is essential to identify a failing implant in time to avoid continuous alveolar bone loss which might complicate the option of replacing the failed implant with a new one as well as impair the esthetic outcome of the area.

\section{Implant replacement}

The success of implants replacing failed ones at the exact site has been reported ${ }^{1,12,13,32,35,46}$. Using the commercially pure titanium screw-shaped implants, it has been suggested that when an implant is lost, a flap should primarily cover the entrance to the site and after 9-12 months, a new implant can be replaced at that site ${ }^{1}$. Evian and $\mathrm{Cutler}^{12}$ report immediately replacing 5 failed screw-type, commercially pure titanium implants with larger-diameter, hydroxyapatitecoated implants in the same sockets. They suggest that a 1year healing period may not be necessary provided the socket can be prepared to eliminate thread grooves and invasive soft tissue; the implant replacement is larger in diameter than the original implant; and sufficient available bone remains for the procedures. Recently, the implant failure rate was compared between a machined surface and a TiUnite surface used to replace failing implants. ${ }^{3}$ Of the 29 machinedsurface implants replaced by implants with the same surface, 6 failed (79.4\% survival rate) compared to the 19 machinedsurface implants replaced by TiUnite surface implants where only 1 failed. Of the 10 TiUnite-surface implants replaced by implants with the same surface, none failed. The difference in failure rate between machined-surface and TiUnite replacement implants was statistically significant.

In a study that assessed survival and success rates of single dental implants replacing a previously failed implant at the same location, an overall survival rate of $71 \%$ was reported with a mean follow-up of $19.4 \pm 11.4$ months $^{16}$.

Replacement of a failing implant involves the challenge of achieving osseointegration in a compromised bone site. When treatment cost and additional procedures to the patient are considered, the clinician needs information regarding the predictability of replacing a failed implant. This information should be discussed with the patient for informed consent for the subsequent attempt.

There is still a lack of sufficient evidence-based data regarding failed implant replacement. Meticulous removal of granulation tissue on the failed implant site and the use of wider implants with improved surfaces could improve the outcome of re-implantation. Further research with a large cohort for a long follow-up period is warranted.

An implant that replaces a previously failed one could serve as a predictable procedure with reasonable survival rates $^{16}$. However, these survival rates are lower than the rates reported for first attempt single implant placement. Clinicians should remember that once an implant has failed, replacement of that implant is subjected to at least all the initial factors that led to the failure.

\section{Other restorative options}

Short arch

When planning implant rehabilitation or when facing implant failure, one should always refer to the question: How many teeth are necessary for adequate function or what dentition assures oral function ${ }^{21}$ ? In some instances, the treated area can remain edentulous and this should be considered as an option. A key indicator of oral health status is the number of teeth ${ }^{37,48}$. In 1992, the World Health Organization (WHO) stated that throughout life, the retention of a functional, esthetic, natural dentition of 20 teeth, without requiring prostheses, should be the treatment goal for oral health ${ }^{48}$. Therefore, 20 teeth have been used as an operative expression for a functional natural dentition in epidemiological studies ${ }^{37,42,43}$.

After extensive review of the literature, Elias andSheiham ${ }^{10}$ concluded that to satisfy oral functional needs a complete dentition is not necessary, which is in accordance with others who suggest that middle-aged and older adults have sufficient oral function with 20 natural teeth, and question the need to replace missing molars ${ }^{4,47}$. However, the demand for tooth replacement was assessed under normative and theoretical conditions, rather than among patients who had experienced tooth loss.

The relationship between dentition and oral function has been evaluated in a review, and concludes that the World Health Organization goal for the year 2000, namely to maintain a natural dentition of not less than 20 teeth throughout life, is substantiated by the current literature since this proposed dentition will assure an acceptable level of oral function ${ }^{14}$. This should also be remembered when dealing with implant failure.

\section{Fixed partial denture}

The alternative use of fixed partial denture (FPD), if applicable, is another treatment modality. Recently, a 
thorough systematic review was conducted that analyzed and compared the survival and success rates of different designs of tooth and implant-supported fixed reconstructions and assessed the incidence of biological and technical complications of FPDs and dental implants ${ }^{38}$. The incidence of technical complications was significantly higher for the implant-supported reconstructions compared with tooth-supported FPDs. In another review that analyzed tooth loss and evaluated the longevity of healthy teeth and teeth compromised by diseases and influenced by therapy and oral implants, found that unless affected by oral diseases or service interventions, teeth will last for life. Numerous retained teeth could be an indicator of positive oral health behavior throughout life. Tooth longevity is largely dependent on the health status of the periodontium, pulp or periapical region, and extent of reconstructions. Multiple risks lead to a critical appraisal of the value of a tooth.

Oral implants when evaluated after 10 years of service present with a longevity that does not surpass that of even compromised, but successfully treated and maintained teeth $^{18}$.

\section{Removable denture}

Removable partial dentures (RPDs) are still extensively used for the restoration of partially edentulous patients. However, these prostheses have been associated with poor patient acceptance, compromised function and esthetics, and increased risk for caries and periodontal disease $\mathrm{e}^{8,26,45,50}$.

Clinicians and dental educators have debated the necessity of using and teaching removable prosthodontics for the partially edentulous patient in today's implant era ${ }^{15}$. Some even consider the art of removable prosthodontics as obsolete. ${ }^{7}$ However, there is an increased need for the management of partially edentulous patients ${ }^{8}$, which is due to the increase in life expectancy and the well-documented decline in tooth loss and total edentulism in the US over the past several decades ${ }^{5,28}$. Adults in the US retain approximately 2.0 more teeth every decade, which explains the unmet need of 516 million chairside hours estimated for prosthodontic treatment alone in the US by 2010 , and the increase to 5060 million hours by $2020^{8}$. Approximately $66 \%$ of this unmet need is for FPDs and 34\% for RPDs ${ }^{8}$.

Despite the obvious need for RPDs, a detailed search of the dental literature failed to elicit strong evidence-based indications for treating the partially edentolous patient with a conventional clasp-retained RPD. ${ }^{49}$ When implants fail or are not an option and economic considerations preclude extensive fixed restorations, RPDs are a valid treatment alternative.

The combination of dental implants to support the RPD may alleviate some of the problems associated with the conventional RPDs ${ }^{17}$. (RPD)

Implant tooth-supported removable partial denture

The problematic long-term clinical experience of restoring partially edentulous patients with RPDs in the era when implants are predictably used for the same patient group suggests the use of implants in combination with RPDs.
Implants are used to improve the RPD support, enhance retention and stability, preserve the residual ridge underneath the denture base, reduce the stress applied on the abutment teeth, eliminate the need for un-esthetic clasp assemblies, and modify unfavorable arch configurations. Generally, RPDs are still needed in cases of un-replaced failed implants, or where economic, systemic, or local anatomic conditions preclude the use of extensive rehabilitation with fixed implant-supported restorations.

Laboratory and clinical studies show the effectiveness of implant-supported RPDs ${ }^{27,30,31,36}$. In model laboratory studies, distally-placed implants supporting a mandibular Kennedy Class I RPDs prevented displacement of the distal extension implant-supported RPDs, improved occlusal support, and decreased the pressure on soft tissues compared to conventional RPDs ${ }^{27,36}$.

In a retrospective clinical study, 10 patients were treated with uni- and bi-lateral mandibular distal-extension RPDs supported by 16 posterior implants ${ }^{31}$. Implants were used as either vertical stops to enhance the prosthesis support or with resilient retentive elements. There was consistently increased satisfaction in all patients, minimal component wear, no radiographic evidence of excessive bone loss around the implants, and stable peri-implant soft tissues. In another study, 15 partially edentulous patients with an unfavorable number and distribution of abutments were treated with implant-supported RPDs ${ }^{30}$. The partially edentulous arch configuration was modified by placing 33 implants into strategic sites. An implant survival rate of $100 \%$ was reported, with only minor prosthetic complications and significantly improved patient satisfaction.

In a case series ${ }^{17}, 23$ implant-supported RPD were placed in 44 implants during a 10-year period (1996-2005). Maxillary restorations were provided to 13 patients and mandibular to 10 patients. Before implant placement, the most prevalent arch configuration was Kennedy Class I in the maxilla (6 patients) followed by Kennedy Class II in the mandible (4 patients). Arch configuration was modified by implant placement in $6(26.1 \%)$ patients. Survival rate was $95.5 \%$; only two implants did not survive, both in a heavy smoker with pre-existing periodontal disease. During follow-up, only one abutment tooth was lost. All other abutments remained in function with no need for re-treatment during the last recall. All patients were highly satisfied with the restoration. According to our findings ${ }^{17}$, we suggest that implantsupported RPD could serve as a long-term predictable treatment modality. Nevertheless, a long-term multi-center study is recommended to evaluate the success of this treatment modality in a larger patient sample. Prospective clinical studies should focus on abutment longevity and need for prosthesis maintenance.

\section{CONCLUSIONS}

Implant therapy has become common practice and will probably gain in popularity during the next several years. This implies that dental professionals will have to deal more 
with implant failure and related complications. When an implant fails, a tailor made treatment plan should be provided to each patient according to all relevant variables. Patients should be informed regarding all possible treatment modalities after implant failure and give their consent to the most appropriate treatment option for them.

\section{ACKNOWLEDGMENTS}

I would like to thank my research colleagues and associates in the field of implant dentistry; especially Dr. Devorah Schwartz-Arad and Dr. Yoav Grossmann for their guidance, assistance and collaboration during the years. I would also like to thank Ms. Rita Lazar for the scientific editorial assistance and for her profound help in preparing this manuscript.

\section{REFERENCES}

1- Adell R, Lekholm U, Rockler B, Bränemark P-I. A 15-year study of osseointegrated implants in the treatment of the edentulous jaw. Int J Oral Surg. 1981;10:387-416.

2- Albrektsson T, Zarb G, Worthington P, Eriksson AR. The long term efficacy of currently used dental implants: a review and proposed criteria of success. Int J Oral Maxillofac Implants. 1986;1:11-25.

3- Alsaadi G, Quirynen M, van Steenberghe D. The importance of implant surface characteristics in the replacement of failed implants. Int J Oral Maxillofac Implants. 2006;21:270-4.

4- Armellini D, von Frauenhofer JA. The shortened dental arch: a review of the literature. J Prosthet Dent. 2004;92:531-5.

5- Beltran-Aguilar ED, Barker LK, Canto MT, Dye BA, Gooch BF, Griffin SO, et al. Surveillance for dental caries, dental sealants, tooth retention, edentulism, and enamel fluorosis-United States, 19881994 and 1999-2002. MMWR Surveill Summ. 2005;54:1-43.

6- Bergman B, Hugoson A, Olsson CO. Caries and periodontal status in patients fitted with removable partial dentures. J Clin Periodontol. 1977;4:134-46.

7- Christensen GJ. Removable prosthodontics: a forgotten part of dentistry. Alpha Omegan. 2006;99:26-8.

8- Douglass CW, Watson AJ. Future needs for fixed and removable partial dentures in the United States. J Prosthet Dent. 2002;87:9-14.

9- Duyck J, Naert I. Failure of oral implants: aetiology, symptoms and influencing factors. Clin Oral Invest. 1998;2:102-14.

10- Elias AC, Sheiham A. The relationship between satisfaction with mouth and number and position of teeth. J Oral Rehabil. 1998;25:64961

11 - Esposito M, Grusovin MG, Coulthard P, Thomsen P, Worthington HV. A 5-year follow-up comparative analysis of the efficacy of various osseointegrated dental implant systems: a systematic review of randomized controlled clinical trials. Int J Oral Maxillofac Implants. $2005 ; 20: 557-68$

12 - Evian CI, Cutler SA. Direct replacement of failed CP titanium implants with larger-diameter, HA-coated Ti-6Al-4V implants: report of five cases. Int J Oral Maxillofac Implants. 1995;10:736-43.
13 - Glavas P, Moses MS. Stage I indexing to replace a failed implant in an edentulous arch: a clinical report. J Prosthet Dent. 2003;89:533-

14- Gotfredsen K, Walls AWG. What dentition assures oral function? Clin Oral Implants Res. 2007;18(Suppl. 3):34-45

15- Graser GN. Predoctoral removable prosthodontics education. J Prosthet Dent. 1990;64:326-33.

16- Grossmann Y, Levin L. Success and survival of single dental implants placed in sites of previously failed implants. J Periodontol. 2007;78(9):1670-4.

17- Grossmann Y, Sadan A, Levin L. A retrospective case series of implants to restore partially edentulous patients with implant supported removable partial denture: 31 - month mean follow-up results. Quintessence Int. (September 2008; in press).

18- Holm-Pedersen P, Lang NP, Müller F. What are the longevities of teeth and oral implants? Clin Oral Implants Res. 2007;18(Suppl. 3): $15-9$.

19- Jemt T, Hager P. Early complete failures of fixed implantsupported prostheses in the edentulous maxilla: a 3-year analysis of 17 consecutive cluster failure patients. Clin Implant Dent Relat Res. 2006;8:77-86.

20- Karoussis IK, Brägger U, Salvi GE, Burgin W, Lang NP. Effect of implant design on survival and success rates of titanium oral implants: a 10-year prospective cohort study of the ITI Dental Implant System. Clin Oral Implants Res. 2004;15:8-17.

21 - Kayser AF. Shortened dental arches and oral function. J Oral Rehabil. 1981;8:457-62

22- Levin L, Schwartz-Arad D. The effect of cigarette smoking on dental implants and related surgery. Implant Dent. 2005;14(4):35761

23 - Levin L, Laviv A, Schwartz-Arad D. Long-term success of implants replacing a single molar. J Periodontol. 2006;77(9):1528-32.

24 - Levin L, Pathael S, Dolev E, Schwartz-Arad D. Aesthetic versus surgical success of single dental implants: 1- to 9-year follow-up. Pract Proced Aesthet Dent. 2005;17:533-8.

25- Levin L, Sadet P, Grossmann Y. A retrospective evaluation of 1387 single-tooth implants: A six-year follow up. J Periodontol. 2006;77:2080-3.

26- Liedberg B, Stoltze K, Owall B. The masticatory handicap of wearing removable dentures in elderly men. Gerodontology. 2005;22:10-6.

27- Maeda Y, Sogo M, Tsutsumi S. Efficacy of a posterior implant support for extra shortened dental arches: a biomechanical model analysis. J Oral Rehabil. 2005;32:656-60.

28 - Marcus SE, Drury TF, Brown LJ, Zion GR. Tooth retention and tooth loss in the permanent dentition of adults: United States, 19881991. J Dent Res. 1996;75:684-95.

29- Mayer TM, Hawley CE, Gunsolley JC, Feldman S. The singletooth implant: A viable alternative for single tooth replacement. J Periodontol. 2002;73:687-93.

30 - Mijiritsky E, Ormianer Z, Klinger A, Mardinger O. Use of dental implants to improve unfavorable removable partial denture design. Compend Contin Educ Dent. 2005;26:744-50. 
31 - Mitrani R, Brudvik JS, Phillips KM. Posterior implants for distal extension removable prostheses: a retrospective study. Int J Periodontics Restorative Dent. 2003;23:353-9.

32- Muroff FI. Removal and replacement of a fractured dental implant: case report. Implant Dent. 2003;12:206-10.

33- Nitzan D, Mamlider A, Levin L, Schwartz-Arad D. Impact of smoking on marginal bone loss. Int J Maxillofac Implants. 2005;20:605-9

34- Norton MR. Biologic and mechanical stability of single tooth implants: 4- to 7-year follow-up. Clin Implant Dent Relat Res. $2001 ; 3: 214-20$.

35-Ogunsalu C. Reimplantation and immediate loading of an accidentally avulsed beaded implant: case report. Implant Dent. 2004; 13:54-7.

36- Ohkubo C, Kurihara D, Shimpo H, Suzuki Y, Kokubo Y, Hosoi T. Effect of implant support on distal extension removable partial dentures: in vitro assessment. J Oral Rehabil. 2007;34:52-6.

37- Petersen PE, Kjoller M, Christensen LB, Krustrup U. Changing dentate status of adults, use of dental health services, and achievement of national dental health goals in Denmark by year 2000. J Public Health Dent. 2004;64:127-35.

38- Pjetursson BE, Brägger U, Lang NP, Zwahlen M. Comparison of survival and complication rates of tooth supported fixed dental prostheses (FDPs) and implant supported FDPs and single crowns (SCs). Clin Oral Implants Res. 2007;18(Suppl. 3):97-113.

39- Porter JA, von Fraunhofer JA. Success or failure of dental implants? A literature review with treatment considerations. Gen Dent. 2005;53:423-32.

40- Romeo E, Lops D, Margutti E, Ghisolfi M, Chiapasco M, Vogel G. Long-term survival and success of oral implants in the treatment of full and partial arches: a 7-year prospective study with the ITI dental implant system .Int J Oral Maxillofac Implants. 2004;19:24759.

41 - Schwartz-Arad D, Herzberg R, Levin L. Evaluation of long-term implant success. J Periodontol. 2005;76(10):1623-8.

42-Sheiham A, Steele JG, Marcenes W, Finch S, Walls AW. The impact of oral health on stated ability to eat certain foods; findings from the national diet and nutrition survey of older people in Great Britain. Gerodontology. 1999;16:11-20.

43- Shimazaki Y, Soh I, Saito T, Yamashita Y, Koga T, Miyazaki H, et al. Influence of dentition status on physical disability, mental impairment, and mortality in institutionalized elderly people. J Dent Res. 2001;80:340-5.

44- Tonetti MS. Determination of the success and failure of rootform osseointegrated dental implants. Adv Dent Res. 1999;13:17380 .

45- Vermeulen AH, Keltjens HM, van't Hof MA, Kayser AF. Tenyear evaluation of removable partial dentures: survival rates based on retreatment, not wearing and replacement. J Prosthet Dent. 1996;76:267-72.

46- Watanabe F, Hata Y, Mataga I, Yoshie S. Retrieval and replacement of a malpositioned dental implant: a clinical report. J Prosthet Dent. 2002;88:255-8.

47- Witter DJ, van Palenstein Helderman WH, Creugers NH, Kayser AF. The shortened dental arch concept and its implications for oral health care. Community Dent Oral Epidemiol. 1999;27:249-58.
48 - World Health Organization. Recent advances in oral health. WHO Technical Report Series. No. 826. WHO, Geneva;1992. p. 16-7.

49- Wostmann B, Budtz-Jorgensen E, Jepson N, Mushimoto E, Palmqvist $\mathrm{S}$, Sofou A, et al. Indications for removable partial dentures: a literature review. Int J Prosthodont. 2005;18:139-45.

50-Zlataric DK, Celebic A, Valentic-Peruzovic M. The effect of removable partial dentures on periodontal health of abutment and non-abutment teeth. J Periodontol. 2002;73:137-44. 